\title{
Arabic Anaphora: Discourse Subduing Morpho-Syntactic Interaction
}

\author{
Naser N. AlBzour ${ }^{1}$ \\ ${ }^{1}$ Assistant professor of Linguistics \& Translation Studies, Department of English Language \& Literature, AABU, \\ Mafraq, Jordan \\ Correspondence: Naser N. AlBzour, Assistant professor of Linguistics \& Translation Studies, Department of \\ English Language \& Literature, AABU, 25113, P. O. Box 130207, Mafraq, Jordan. Tel: 962-2-629-7000 ext. \\ 2220. E-mail: nnnbzour@gmail.com
}

\author{
Received: April 28, 2015 Accepted: May 24, 2015 Online Published: August 31, 2015 \\ doi:10.5539/ells.v5n3p38 URL: http://dx.doi.org/10.5539/ells.v5n3p38
}

\begin{abstract}
This succinct paper primarily examines the discoursal impact proper on the morpho-syntactic behavior of reflexives in Arabic. It specifically explores the interrelatedness between topicalization as well as morpho-syntactic interaction that can delineate the movement of these reflexives within the Government and Binding framework and its crucial bearings on the subsequent minimalist approach. The study shows how this morphosyntactic interaction is subtly active in licensing $D P$ movement in Standard Arabic unlike Jordanian Arabic where the lack of inflectional morphology often aborts such relevant movements. The study, furthermore, provides tangible syntactic evidence that this kind of movement, though pragmatically and discoursally motivated in the first place, does comply with syntactic constraints that restrict its operations within the $C P$ domain; thus excluding any proposals that advocate stacking argument in Arabic.
\end{abstract}

Keywords: anaphora, discourse, government and binding, movement, morpho-syntactic, topicalization

\section{Introduction}

Chomsky's work is one of the most remarkable intellectual achievements of the present era ... it has created a new discipline of generative grammar and is having a revolutionary effect on two other subjects, philosophy and psychology. Not the least of its merits is that it provides an extremely powerful tool even for those who disagree with many features of Chomsky's approach to language. (John Searle)

One of the most crucial landmarks in the history of modern linguistics was the advent of Generative grammar in 1950s. The antagonistic spirit that marked the tug-war relationship between generativists and structuralists has lasted for decades and decades. The real birth and growth of functional approaches in 1980s was of paramount importance as it tends to broaden linguistic perspectives and thus to incorporate and sometimes to synthesize both generative and structural assumptions that may facilitate any deeper understanding of language dynamics.

All through those past decades, the propelling trend of Chomskyan generative school of grammar has been dominantly proposing and establishing deeply-rooted theories and principles that aim at serving Chomsky's syntactic claims and hypotheses per se, the evident core of which is embodied in his insight about Universal Grammar (Chomsky, 1957, 1981). Of course, the ultimate goal of $\mathbf{U G}$ is definitely to rationalize the economicality of grammatical tools needed to generate well vs. ill-forms as an indubitable axiom of natural faculty and human innateness (Chomsky, 1995, 2000, 2001). There is no doubt that Arabic and English are syntactically well- organized, but English is relatively morphologically impoverished in terms of its inflectional diversity and specificity. Therefore, Arabic syntactic structure combined with a plethora of its morphological tools and instigated by discoursal motivations may interact and thus all lend themselves to Binding Theory in a uniquely different manner. This topic exhibits multifaceted dimensions that many serious research works would be needed to cover thoroughly; however, the researcher tries in this paper to shed light on some fundamental aspects of these anaphoric expressions within the frame of Binding Theory, to illustrate the milestones of two of its three principles, namely, Principle A and Principle B as elicited by Lasnik (1999) and Huang (2000) with a particular reference to Standard Arabic (henceforth, SA) and Jordanian Arabic (henceforth, JA) data that may show convergence or/ and divergence at certain levels in supporting or refuting these principles. 


\section{Method and Limitation of the Study}

The data used in this study have been taken from Jordanian daily discourse and have been attested by fifty Jordanian informants, $30 \mathrm{BA}$ students, $10 \mathrm{MA}$ students and 10 professors of Arabic language and English linguistics, in order to avoid any controversial argument concerning the validity and the reliability of such data and the subsequent analyses. Therefore, the data owe particular reference to SA in the first place because SA intricately reflects this overt interaction, and of course with simultaneous reference to Jordanian Arabic where relatively minimal interaction is expected to show convergence or/ and divergence at certain levels in supporting the role of morphology in licensing or prohibiting certain movements. It is worth noting that phonological distinctions between these two dialects will be explicitly neutralized in many of these data to avoid extra-complicated possible morpho-phonological interaction which is beyond the scope of this study. These two varieties of Arabic operate differently to some extent in exploiting anaphoric expressions due to the basic distinctive roles of morphological markers which evidently and subtly exist in SA to elaborately mark syntactic concordance of every single word with its antecedents in terms gender, number, tense and case unlike many vernaculars such as JA. It is hoped that this preliminary brief work will give insight into further comprehensive research endeavors to deeply examine various aspects of Arabic Language in the near future since very little has been done in these fields of discoursally oriented syntactic studies. This paper by no means aims at annulling or refuting any previous syntactic argumentation proper; rather, it endeavors to incorporate some other interdisciplinary analyses that can better cater for such linguistic phenomenon.

\section{Assumptions and Results}

All the data collected by the researcher have been closely examined within the dominant linguistic assumptions and implications of the generative approach. A very keen and cautious categorization has of the JA and SA data has been made in order to appropriately conceive the subtle similarities and the differences between the two dialects so that precise generalizations can be made in the final analysis.

\subsection{Basic Arabic Sentence Structure}

Both SA and JA in principle share the template VSO, along with SVO which is quite a common structure as well. This has led to a controversy whether Arabic is underlyingly SVO (see Benmamoun, 2000). The third sentence pattern is called 'nominal sentence template' where no verbs surface in such sentences, but this is beyond the scope of this study. Sentences (1.a) and (1.b) in SA below show clearly how this alternation between the subject and the verb smoothly occur in Arabic. For most Arab speakers (whether standard Arabic or any vernacular), these two sentences can be judged equally grammatical without marking any significant syntactic distinction as such. However, the VSO construction in the indicative mood is marked ungrammatical for any speaker of English.

(1)

a. HaDar - a al- walad u
came T. Mark the boy Nom.mark
The boy came
b. al- walad u HaDar - a
the boy Nom.mark came T. Mark
The boy came
c. najaH el- walad
succeeded the boy

The boy succeeded

b. el- walad najaH

the boy succeeded

The boy succeeded

One can notice the existence of inflectional morphemes suffixed to the verb and the subject in SA unlike all spoken Arabic dialects, which entirely lack such morphological markers as it can be seen in (1.c) and (1.d). 


\subsection{Little Pro}

Arabic pro (null finite subject) is so prevalent and easily understood in terms of gender and number because it only occurs with the singular (feminine or masculine). In traditional grammar, this phenomenon is expressed as a covert pronoun occupying the subject or the object position. The significant relevance of this pro is its crucial role in demarcating the binding domain of the reflexives as it will be elicited in the body of the binding discussion.

(2)

$$
\begin{array}{rlc}
\text { a. HaDar } & -(a) & \text { pro albariHa } \\
\text { came } & \text { T. Mark } & \text { PRO yesterday } \\
\text { b. HaDar } & \text { pro } & \text { albariHa } \\
\text { came } & \text { pro } & \text { yesterday }
\end{array}
$$

He came yesterday.

$$
\begin{aligned}
& \text { c. HaDar - (a- a) albariHa } \\
& \text { came PstT. Dual (They) yesterday } \\
& \text { They (dual) Msc came yesterday. } \\
& \text { d. HaDar u } \quad \text { - albariHa } \\
& \text { came PstT. Pl yesterday }
\end{aligned}
$$

They (dual or PL) came yesterday.

$$
\begin{aligned}
& \text { e. HaDar u - u albariHa } \\
& \text { came PstT. Pl (They) yesterda } \\
& \text { They( } 3 \text { or more) came yesterday. }
\end{aligned}
$$

$$
\begin{array}{ccr}
\text { f. HaDar } & \text { u } & - \\
\text { came PstT. } & \text { Pl (They) } & \text { yesterdaY }
\end{array}
$$

They came yesterday.

Examining these six sentences, one can promptly realize that in both SA and JA little pro optionally occurs and interpreted as third person singular 'he' as in (a) and (b) respectively. However, the pronominal clitic in the rest of these sentences (c-f) is morphologically and distinctively marked as dual or plural in SA while in JA the morphological distinction is somehow amorphous.

\subsection{Morphology \& Syntax}

These two varieties of Arabic operate differently to a great extent in exploiting inflectional morphemes due to the basic distinctive roles of morphological markers, which evidently and subtly exist to presumably mark every single word in (SA) unlike (JA) and many other vernaculars.

\subsubsection{Inflections}

As it has already been mentioned, the following sentences (a-c) demonstrate how agreement is realized between the subject and the verb in terms of case, tense, number and gender in SA, number distinction is partially realized in $\mathbf{J A}$ in (d). The most important issue to be pinpointed pertaining to our study is case marking, which is absolutely absent in $\mathbf{J A}$.

(3)

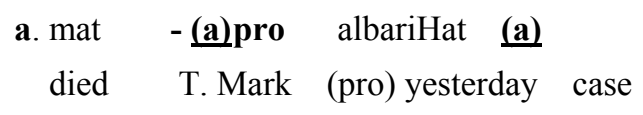

He died yesterday.

$$
\begin{aligned}
& \text { b. mat }-\underline{(\mathbf{a}-\quad \text { a) }} \quad \text { albariHat } \quad \underline{\text { (a) }} \\
& \text { died PstT. Dual (They) yesterday case }
\end{aligned}
$$

They (two) died yesterday.

\section{(SA)}




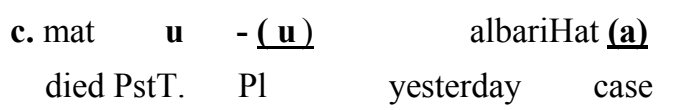

They ( two or more) died yesterday.

d. mat u - albariHa

died PstT. Pl (They) yesterday

They died yesterday.
(SA)

(JA)

\subsubsection{Reflexives \& Case}

Case markers play a very significant role in marking the end of every single word in SA except when occasional pauses and junctures occur. Using such morphological affixes appropriately or inappropriately can be deemed as hard evidence to judge whether the speaker is a native speaker of SA or not. Reflexive Pronouns occur only in the accusative form either as complements of transitive verbs in VPs or complements of prepositions in PPs as in (4.a \& 4.b) and (4.c \& 4.d) respectively. Case markers in SA can be realized linearly in forms of suffixes or infixes, of course.

(4)

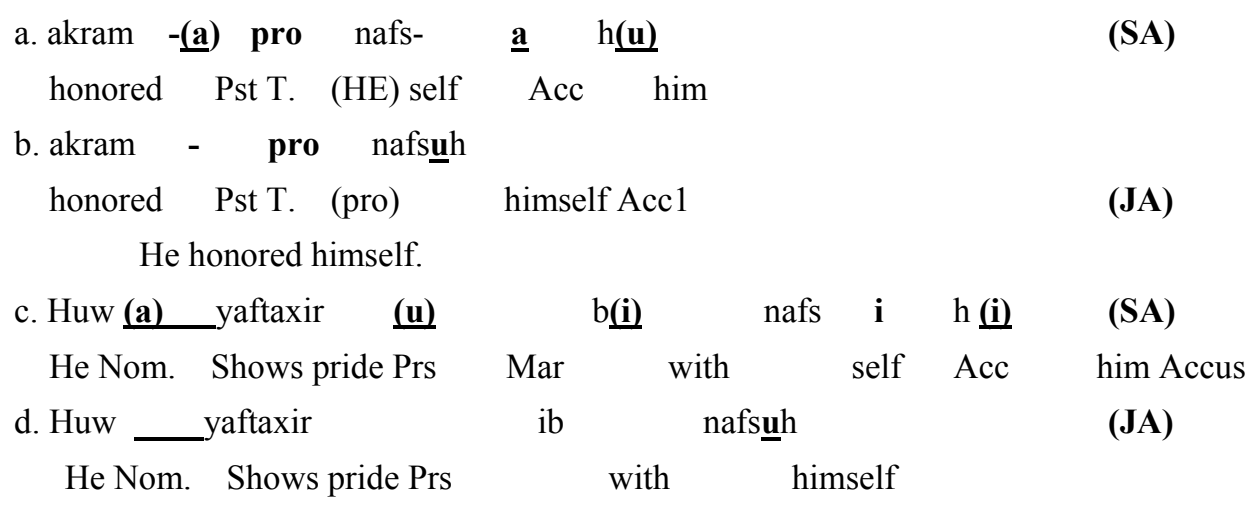

He is proud of himself.

It is essential to understand that different morphemes are used to mark different cases in $\mathbf{S A}$, for instance the morpheme ' $\mathbf{a}$ ' in the first sentence. On the contrary, the infix ' $\mathbf{u}$ ' in $\mathbf{J A}(\mathrm{b} \& \mathrm{~d})$ is in fact a phoneme rather than a morpheme and it marks no case, unlike $\mathbf{S A}$ where this infix i.e. ' $\mathbf{u}$ ' marks the nominative case.

\subsubsection{SA Reflexives}

To avoid any kind of misconception, it would be useful at this level to briefly introduce the grammatical structure of reflexives in Arabic. In a nutshell, these reflexives in (SA) are formed by building up a combination of the genitive form of the stem 'nafs'(self), and the appropriate personal pronoun that meets concordance principles in terms of number and gender. Therefore and in addition to its role in X-position as it can be seen in our analysis, morphology plays a significant role in determining the right form as it can be seen below when reflexives occur as VP-Complement as in 5 (a-p):

(5)

a. Nafs-a-hu (self+ ' $3{ }^{\text {rd }} \operatorname{Pr}$,SG.masc.' he/him) $=$ himself

b. Nafs-a-ha (self+ ' $3{ }^{\text {rd }} \mathrm{Pr}$,SG.fem.' she/her) =herself

c. Nafs-ay-huma(nafs $+{ }^{\text {‘ }} 3{ }^{\text {rd }} \mathrm{Pr}$,dual.masc.' they/them) themselves

d. Nafs-ay-huma(nafs+' $3{ }^{\text {rd }} \mathrm{Pr}$, dual.fem.' they/them) themselves

e. Anfus-a-hum(nafs+' $3{ }^{\text {rd }} P r, P L . m a s c . '$ they/them) themselves

f. Anfus-a-hunna(nafs + ' $3{ }^{\text {rd }} \operatorname{Pr}$,PL.fem.' they/them) themselves

g. Nafs-a-ka (nafs+ ' 2 nd $P r, S G . m a s c . '$ you/your) yourself

h. Nafs-aki (nafs+ ' 2 nd $P r$,SG.fem.' you/your) yourself

i. Anfus-a-kuma(nafs $+2{ }^{\text {nd }} \operatorname{Pr}$,dual.masc.' you/your) yourselves

j. Anfus-a-kuma(nafs+ ${ }^{\text {‘ }} 2{ }^{\text {nd }} \mathrm{Pr}$, dual.feminine.'your) yourselves 
k. Anfus-a-kum(nafs $+2^{\text {nd }}$ Pr,PL.masc.' you/your) yourselves

1. Anfus-a-kunna(nafs $+{ }^{\text {‘ }}{ }^{\text {nd }}$ Pr,PL.fem.'you/your) yourselves

m. nafs-i (nafs + ' 1 st $\quad$ Pr,SG.masc.'my) myself

n. nafs-i (nafs + ' 1 st $\quad$ Pr,SG.fem.' I/my) myself

o. anfus-a-na (nafs+ ' 1 st Pr,PL.masc.'we/our) ourselves

p. anfus-a-na (nafs+ ' $1^{\text {st }}$ Pr,PL.fem.'we/our) ourselves

Because (SA), makes morphological distinctions between the accusative case of compliments of transitive verbs in VPs and compliments of prepositions in PP-Complement, the following examples show in (6) another set of forms used to represent the latter:

(6)

a. Nafs-i-hi (self+ ' $3{ }^{\text {rd }} \operatorname{Pr}$,SG.masc.' he/him) $=$ himself

b. Nafs-i-ha (self+ ' $3{ }^{\text {rd }} \mathrm{Pr}$,SG.fem.' she/her) $=$ herself

c. Nafs-ay-hima(nafs $+{ }^{\prime} 3{ }^{\text {rd }} \mathrm{Pr}$, dual.masc.' they/them) themselves

d. Nafs-ay-hima(nafs+' $3{ }^{\text {rd }} \operatorname{Pr}$,dual.fem.' they/them) themselves

e. Anfus-i-hum(nafs+' $3{ }^{\text {rd }} \operatorname{Pr}, P L$.masc.' they/them) themselves

f. Anfus-i-hunna(nafs $+{ }^{\prime} 3{ }^{\text {rd }} \mathrm{Pr}$,PL.fem.' they/them) themselves

g. Nafs-i-ka (nafs+ ' $2{ }^{\text {nd }} \operatorname{Pr}, S G . m a s c . '$ you/your) yourself

h. Nafs-i-ki (nafs + ' 2 nd $P r, S G . f e m . '$ you/your) yourself

i. Anfus-i-kuma(nafs $+2^{\text {nd }} \operatorname{Pr}$,dual.masc.' you/your) yourselves

j. Anfus-i-kuma(nafs $+{ }^{\text {' }} 2{ }^{\text {nd }} \operatorname{Pr}$, dual.feminine.' your) yourselves

k. Anfus-i-kum(nafs+' $2{ }^{\text {nd }}$ Pr,PL.masc.' you/your) yourselves

1. Anfus-i-kunna(nafs $+{ }^{\prime} 2^{\text {nd }} \operatorname{Pr}, P L . f e m$.'you/your) yourselves

m. nafs-i (nafs + ' $1{ }^{\text {st }} \quad$ Pr,SG.masc.'my) myself

n. nafs-i (nafs+ ' $1^{\text {st }} \quad$ Pr,SG.fem.' I/my) myself

o. anfus-i-na (nafs+ ' $1^{\text {st }}$ Pr,PL.masc.'we/our) ourselves

p. anfus-i-na (nafs $+{ }^{\prime} 1^{\text {st }} \quad$ Pr,PL.fem.'we/our) ourselves

\subsection{JA Reflexives}

As an inevitable consequence of morphological impoverishment in (JA), the subtle distinctions between reflexives in terms of number and gender-let alone case, which doubly diversify the issue in (SA) - is minimally manifested, so the number of these reflexives has been reduced to ten forms in this vernacular dialect as in $7(a-j)$ :

(7)
a. Nafsi- (nafs+' 1 st Pr,SG..' I/my) myself
b. Nafsi- na (nafs+ ' 1 st Pr,PL..' we/our) ourselves
c. Nafs-uh (self+ ' $3{ }^{\text {rd }} \operatorname{Pr}$,SG.masc.' he/him) $=$ himself
d. Nafis-ha (self+ ' $3{ }^{\text {rd }} \operatorname{Pr}$, SG.fem.' she/her) $=$ herself
e. nafis-hum(nafs+' $3{ }^{\text {rd }} \operatorname{Pr}, P L$.masc.' they/them) themselves
f. Anfis-hin(nafs+' $3{ }^{\text {rd }} \operatorname{Pr}$,PL.fem.' they/them) themselves
g. Nafsa-k (nafs+ ' $2{ }^{\text {nd }}$ Pr,SG.masc.' you/your) yourself
h. Nafsi-k (nafs+ ' 2 nd Pr,SG.fem.' you/your) yourself
i. Nafsi-ku (nafs+ ' 2 nd Pr,PL.fem.' you/your) yourself
j. Nafsi-kin(nafs $\left.+{ }^{\prime} 2{ }^{\text {nd }} P r, P L . f e m . ' y o u / y o u r\right)$ yourselves 


\section{Analysis and Discussion}

This section is mainly dedicated to technically discuss and elaborate on the anaphoric morpho-syntactic behavior as stipulated by generativists, as best diagnosed and described by Government \& Binding as well as Minimalist advocates. Accordingly, discoursal assumptions can be traced, highlighted and justified with reference to corresponding syntactic motivations.

\subsection{Reflexives and Principle A}

Principle A of the Binding Theory stipulates that an anaphor must be bound in its local domain or governing category (Chomsky, 1981). The governing category of reflexives in SA is customarily a TP. The GC of a reflexive in SA is the minimal domain containing the reflexive, its governor, and an appropriate antecedent. The assumption of government theory can be laconically summed up as proposed by Haegeman (1991) and Hornstein (2001):

\section{A. An anaphor must be bound in its domain. \\ B. A pronoun must be free in its domain.}

The C-command condition on binding stipulates that a bound element be c-commanded by its antecedent. Consequently, A governs B if and only if:

(i) $A$ is a governor,

(ii) A c-commands B,

(iii) And no barriers intervene between A and B (locally bound without blocking maximal projections).

Haegeman (1991, p. 241) maintains that node A c-commands node B if and only if

(i) A does not dominate $\mathrm{B}$;

(ii) B does not dominate $\mathrm{A}$;

(iii) The first branching node dominating A also dominates B.

\subsection{Binding in Arabic}

This cursory section investigates Binding Theory and its application to Arabic Reflexive anaphors. Therefore, the primary concern of this analysis is to examine some problematic analyses such as Mahmoud's (2000: 147) assumption as he maintains, "condition A and B behave exactly in Arabic as they do in English". As a matter of fact, this claim needs or maybe needs not to be modified since these conditions behave to a considerable extent in Arabic as they do in English, so one might think that there must be some diverging junctures between the two languages due to the different syntactic nature of Arabic which permits both SVO as well as VSO structure, on the one hand. Arabic, on the other hand, allows drastic flexibility of constituents within phrases and clauses due to the distinctly elaborate morphological system of inflections that evidently mark agreement o gender, number and case.

In $\mathbf{S A}$, the antecedent of the reflexive must c-command the reflexive itself. Besides, the antecedent of the reflexive needs to be the closest c-commanding subject to the reflexive (no cross over c-commanding subject), and it needs thus to agree with the reflexive in essential features such as person, number and gender. If the closest c-commanding subject (potential antecedent) does not agree with reflexive in one of the above-mentioned features, the sentence will be automatically marked ungrammatical.

Additionally, reflexive anaphoric expressions in SA are frequently used to augment emphatic meaning which can be conventionally mixed with intensives and labeled as 'tawkeed ma9nawi' (nonverbal emphasis) in traditional books of grammar. There are various stems and forms that can be used in this respect, mainly seven forms, six of them have nothing to do with the syntactic function of anaphors; they are rather exploited for mere emphatic purposes, (cf. Huang, 2000). The researcher will examine only one form of these, mainly, the one which consists of the same stem constituent anaphors with an appropriate clitic pronoun. These reflexives are formed by genitivally combining the stem 'nafs' (self or soul), or less frequently in JA 'Haal' (self/manner) and the appropriate referential clitic pronoun that meets concordance principles in number and gender. This genitive structure surfaces as a possessive form. Therefore, morphology again plays a primary role in determining the right form as it can be seen below in $\mathbf{8}(\mathbf{a}-\mathbf{l})$ :

(8)

a. Nafs-hu (self+ ' $3{ }^{\text {rd }} \mathrm{Pr}$,sing.masc.' he/him) $=$ himself

b. Nafs-ha (self+ ' $3{ }^{\text {rd }} \mathrm{Pr}$,sing.fem.' she/her) $=$ herself 
c. Nafs-huma (nafs+ ' $3{ }^{\text {rd }} \operatorname{Pr}$,dual.masc.' they/them) themselves

d. Nafs-huma (nafs+ ' $3{ }^{\text {rd }} \operatorname{Pr}$,dual.fem.' they/them) themselves

e. Anfus-hum (nafs+ ' $3{ }^{\text {rd }} \operatorname{Pr}$,plur.masc.' they/them) themselves

f. Anfus-hunna (nafs + ' $3{ }^{\text {rd }} \operatorname{Pr}$,plur.fem.'they/them) themselves

g. Nafs-ka (nafs + ' 2 nd $P r$,sing.masc.' you/your) yourself

h. nafsaki (nafs+ ' 2 nd $P r$,sing.fem.' you/your) yourself

i. anfus-kuma(nafs+ ' 2 nd $P r$,dual.masc.' you/your) yourselves

j. anfus-kuma (nafs + ' $2{ }^{\text {nd }} P r$,dual.feminine.' your) yourselves

k. anfus-kum (nafs + ' 2 nd $\operatorname{Pr}$,plur.masc.' you/your) yourselves

1. anfus-kunna (nafs+ ' $2{ }^{\text {nd }} P r$,plur.fem.' you/your) yourselves

m. nafs-i (nafs+ ' $1^{\text {st }}$ Pr,sing.masc.'my) myself

n. nafs-i (nafs + ' $1{ }^{\text {st }}$ Pr,sing.fem.' I/my) myself

o. anfus-na (nafs+ ' 1 st Pr,plur.masc.'we/our) ourselves

p. anfus-na (nafs+ ' 1 st $\quad$ Pr,plur.fem.' we/our) ourselves

(9) A. qatala alwaladu nafsahu (The boy killed himself)

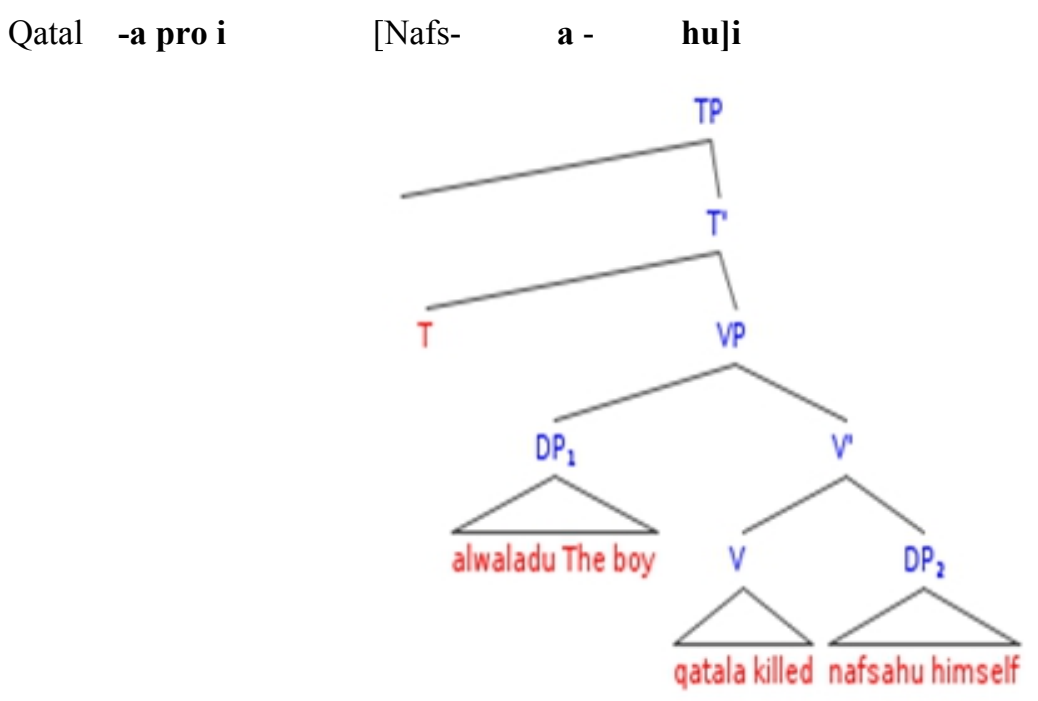

Diagram 1. Where do reflexives originate in SA

(9) B. qatal elwalad nafsuh (The boy killed himself)

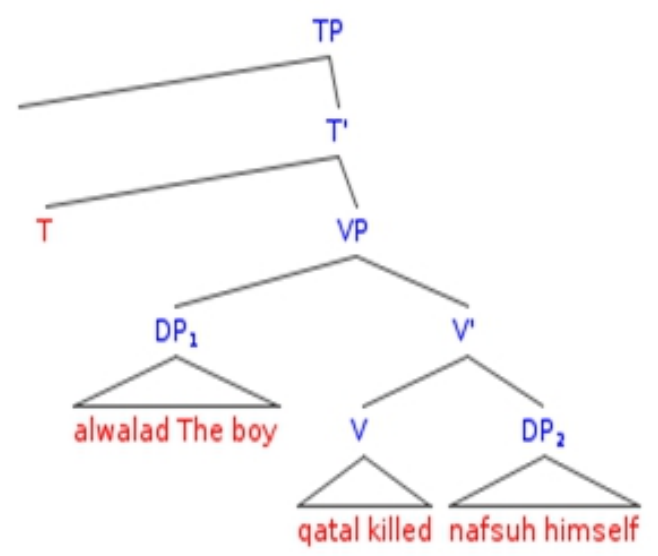

Diagram 2. Where do reflexives originate in JA 
However, the following examples reflect some aspects of the current controversy when the sentence in (9) is manipulated and thus reproduced as in $\mathbf{1 0}$ (a-d) to be acceptable in both SA \& JA and to be ungrammatical or at least anomalous in $\mathbf{1 1}$ (a-d) in JA. These sentences may reveal that such kind of movement and/or X-position is licensed and guaranteed by virtue of morphological inflections that are evidently present in SA and absent in JA.

(10) SA

a. [Nafs- a - hu]i Qatal -a pro i

self - acc. mark- his killed he (3.Sg.M)

Hei killed himselfi

b. [Nafs- a ha] Qatal -at pro i

self - acc. mark- her Killed she(3.Sg.F)

Shei killed herselfi

c. [anfus- a- hum a]i Qatal- aai

self acc,mark their Killed (M.dual)

heyi killed themselvesi.

d. [anfus- a hum]i Qatal - ui

selves acc.mar their Killed (3.pl.M)

Theyi killed themselvesi.

(11) JA

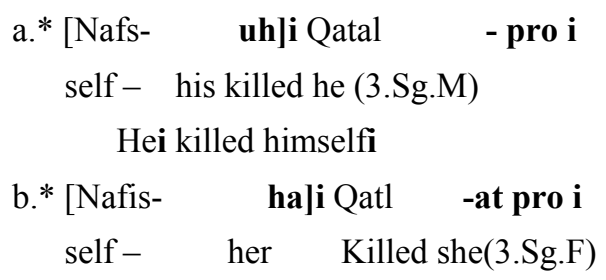

Shei killed herselfi

c. * [anfus- hum ]i Qatal- uui

self their Killed (M.PL/Dual)

Theyi killed themselvesi.

\subsection{Binding and Trace}

The complexity of binding can be aggravated yet explained if null constituents can be appropriately contextualized as it can be explicated in the following segment. It is evident that 'alsabiyu' in 12 (a-b) binds the reflexive 'nafsahu' since the two conditions of coindexation and c-command are fairly met. The binding conditions are not violated in 12 (c) i.e. 'alsabiyu' remains the binder and the trace of the reflexive 'nafsahu' is definitely the bindee in situ. Therefore, the three sentences 12 (a-c) are grammatical in SA.

(12)

a. Qatal-a alSabiy-u i Nafs- a - hu]i

killed the lad.Nom self - acc. mark- his

The ladi killed himselfi

b. alSabiy-u i Qatal-a Nafs- a - hu]i the lad.Nom killed self-acc. mark- his

The ladi killed himselfi

c. [Nafs- a - hu]i Qatal-a alSabiy-ui ti self - acc. mark- his killed the lad.Nom

The ladi killed himself 


\section{$\mathrm{d}^{*}[$ Nafs-a - $\quad$ hu]i $\quad$ Qatal-a pro alSabiy-a \\ self - acc. mark- his killed pro the lad.Acc \\ himselfi killed the ladj $\mathbf{i}$}

The trace of the reflexive in 12(d) proscribes any DP to take its place for two legitimate syntactic reasons. On the one hand, it would be a violation of case assignment concerning Earliness Principle as proposed by Pesetsky (1989 \& 2000) where operations apply 'as early in a derivation as possible'. Therefore, the transitive head 'qatala' must assign an accusative case to the object which it c-commands since this slot has been already reserved for and taken by the reflexive, which has undergone x-position after it had been assigned its case as it can be seen in the following sentence (13) where the reflexive 'himself' and the boy 'alwalada' are assigned an accusative case, so it is ungrammatical:

$\begin{array}{rlllllll}(13) * \text { nafs- } & \text { a } & \text { hu } & \text { lam } & - \text { a } & \text { al } & \text { walad } & -\underline{\text { a }} \\ \text { self } & \underline{A c c M} & \text { him } & \text { blame } & \text { Past M } & \text { the } & \text { boy } & \underline{A c c} \mathrm{M}\end{array}$

*He blamed himself the boy.

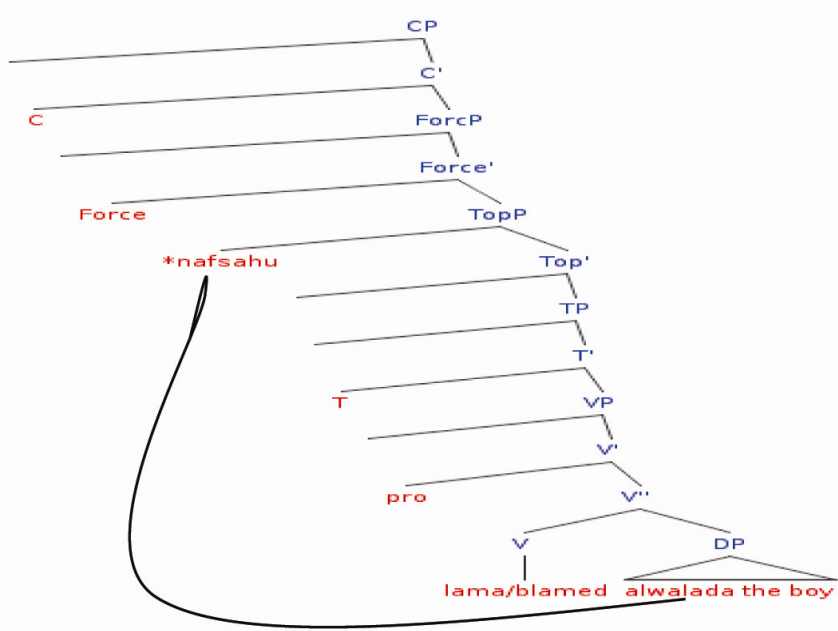

Diagram 3. Inappropriate case marking

On the other hand, having this construction is in utter violation with the theta-criterion because the verb 'qatala' is a transitive verb that requires two arguments (agent \& patient) and it has already assigned the two theta roles to these arguments (agent: pro)and (patient: nafsahu). The sentence can be grammatical if we replace 'alwalad-a' by 'alwalad-u' since the latter becomes the subject/agent and the little pro automatically elides:

\section{(14)}

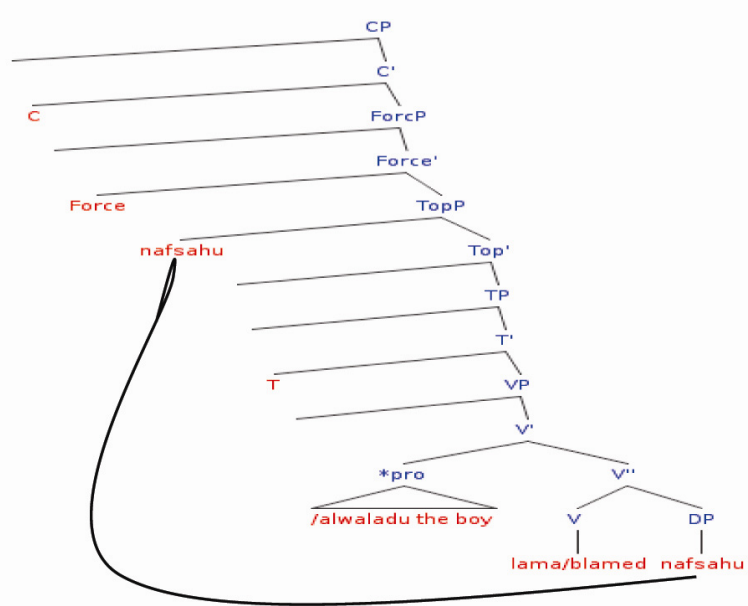

Diagram 4. Theta-assignment 


\subsection{Focus/Topicalization \& A Movement}

We have noticed that this kind of reflexive-movement in SA is morpho-syntactically licensed to achieve particular topicalization discourse functions as it can be illustrated in (15):

(15)

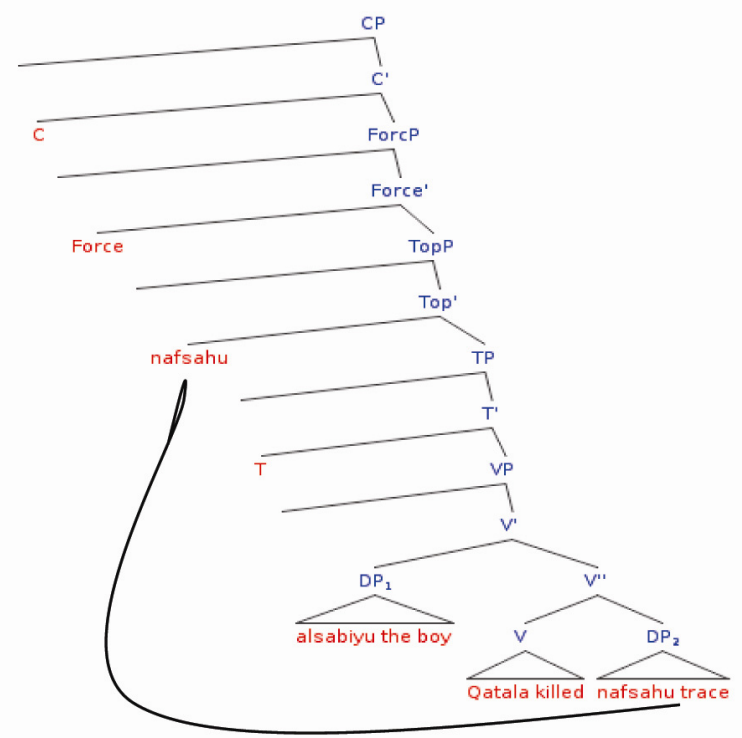

Diagram 5. Focus-motivated movement

Apparently, this might show disparate and parametrical techniques among languages. Following Rizzi (1997) and Cormack and Smith (2000), Radford (2004) assumes that topicalization is a kind of A-bar movement occupying the specifier position within the Topic Phrase.

(16)

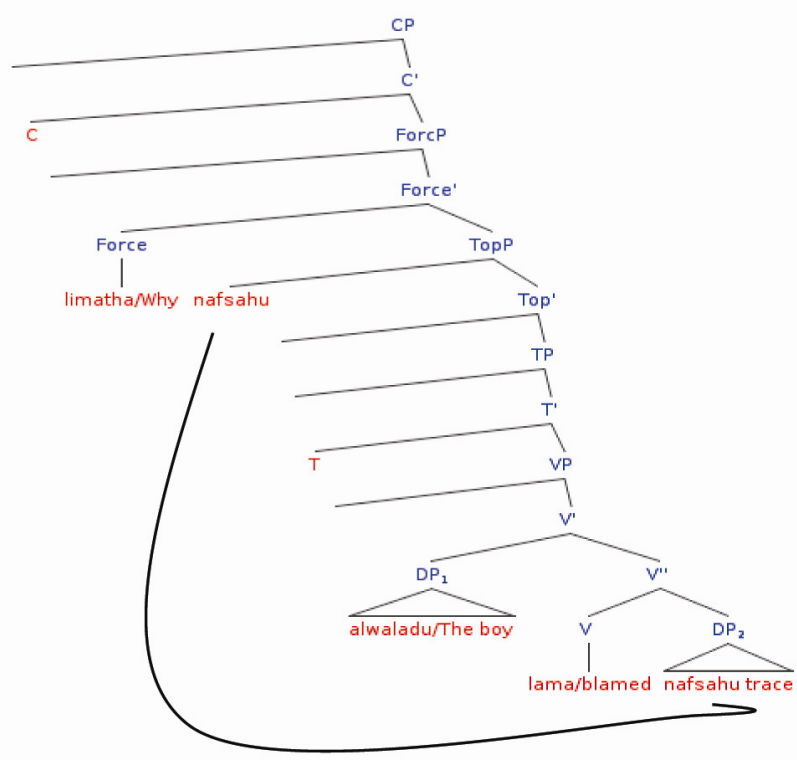

Diagram 6. Movement inside CP

This might be the most feasible proposal for the time being; otherwise, such a phenomenon in Arabic would be stacking rather than movement since stacking can move outside the CP. Strong evidence for reflexive movement within the CP is Wh-Question in Arabic where the Force node is in a higher position than the Focus node; this can rationalize why the reflexive is allowed to move freely within the CP and below the ForcP as in (16); the 
reflexive movement outside the $\mathrm{CP}$ or even higher than the ForcP generates ill-formed structures as it is the case in (17).

(17)

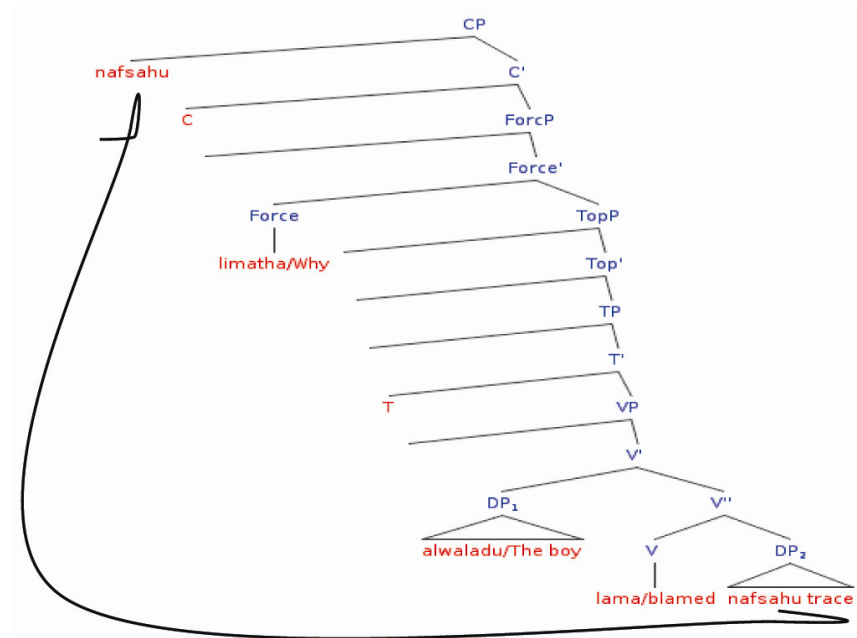

Diagram 7. *Movement outside CP

Topicalization constructions are possibly licensed via intonation and punctuation in many languages, take English for instance, where 18. (a-d) are all well-formed via discoursally and syntactically moving different constituents.

\section{(18)}

a) DP: George, we all love.

b) PP: To George, I gave my notebook.

c) AP: Furious, George will never be.

d) CP: That Georges was an outstanding MA student, I never doubt.

This argument by no means excludes Arabic in the same vein from exploiting intonation and punctuation in topicalization. SA or more specifically Modern SA, in fact tends to use this technique too. This is considered by many zealous Arabs, by Pan-Arabism-obsessed linguists and by perfectionists a manifestation of language contact and syntactic calquing as a result of the irresistible impact of mass media and thus the hegemony of globalization. As a matter of fact, one should not deny that such constructions have been imported through different channels of language contact, yet these issues are symptoms of the natural evolution and enrichment of any language rather than being a pestilential plague or imminent prognosis of the demise of that language.

\subsection{Binder, Reflexives and Definiteness}

We have observed through all these aforementioned examples thus far that reflexives in SA are bound by a definite binder. In brief, definiteness in SA can be attained in three different constructions: proper nouns, proper nouns with the definite article and quasi-genitive (Compounding) as it can be seen in the following examples respectively:

(19)
a. Sara
Proper N Sara
b. Al- xabeer
Def.(The) expert
c. Qarar-u xabeer
decision expert
expert's decision 
The basic issue that definiteness has its evident bearings upon is the fact that moving a reflexive anywhere if the binder is indefinite can ungrammatical even in SA. Consider the grammaticality of 20 (a-c) where the noun 'mu?allim' is given a definite value, so it is grammatical to keep the reflexive in its original complement position as in 20 (a \& b) or to front it as in (c).

(20)

a. 9athara-a al-muiallim-u i Nafs- a - hu]i

excused Def.the teacher.Nom self -acc. mark- his

The teacheri excused himselfi

b. 9athara-a mu?allim-u al-Safi Nafs- a - hu]i

excused teacher.Nom Def- class self-acc.mark- his

[The class teacher]i excused himselfi

c. Nafs- a - hu]i 9athara-a mu?allim-u al-Safi

self-acc.mark- his excused teacher.Nom Def- class

[The class teacher]i excused himself

However, grammaticality is restricted to $21((\mathrm{a})$ where the binder is indefinite, so the reflexive 'nafsahu' has to stay in situ. This very reason is behind the ungrammaticality of $21(\mathrm{~b})$ where the reflexive is being moved although the binder is indefinite.

(21)

a. 9athara-a mu?allim-uni Nafs- a - hu]i

excused teacher.Nom self-acc.mark- his

[A teacher]i excused himselfi

b. *Nafs- a - hu]i 9athara-a mu?allim-uni

self-acc.mark- his excused teacher.Nom

Himselfi a teacheri excused

\section{Conclusion}

To recapitulate, there is no doubt that the subtle morphological role in SA licenses a wide range of 'movements' and thus results in a flexible word order while the lack of such morphology in JA precludes such overt dynamism. The motivation for this DP movement in Arabic is principally pragmatic not syntactic. Syntax and morphology can conspire and give rise to a wide range of focus alternation in SA. Therefore, this kind of movement is not a form of stacking; rather it proves to be a DP movement in minimalist terms because there is hard evidence for such syntactic motivation in Wh-Q where the reflexive movement outside the CP or even higher than the ForceP is absolutely banned because Topic Phrase resides dominated by the Force Phrase.

\section{References}

Benmamoun, E. (2000). The feature structure of functional categories: a comparative study of Arabic dialects. Oxford: Oxford University Press.

Carnie, A. (2013). Syntax: a generative introduction. Oxford: Blackwell Publishing.

Chomsky, N. (1957). Syntactic structures. The Hague: Mouton.

Chomsky, N. (1981). Lectures on government and binding. Dordrecht: Foris.

Chomsky, N. (1986). Knowledge of language: its nature, origin, and use. New York: Praeger.

Chomsky, N. (1995). The minimalist program. Cambridge: MIT Press.

Chomsky, N. (2000). Minimalist inquiries: The framework. In R. Martin, D. Michaels, \& J. Uriagereka (Eds.), Step by step: Essays on minimalist syntax in honor of Howard Lasnik (pp. 89-155). Cambridge: MIT Press.

Chomsky, N. (2001). Derivation by phase. In M. Kenstowicz (Ed.), Ken Hale: A life in language (pp. 1-52). Cambridge: MIT Press.

Cook, V. J., \& Newson, M. (2000). Chomsky's universal grammar. Oxford: Blackwell Publishing. 
Cormack, A., \& Smith, N. (2000). Fronting: the syntax and pragmatics of 'Focus' and 'Topic'. UCL Working Papers in Linguistics, 20, 387-417.

Fassi-Fehri, A. (1993). Issues in the structure of Arabic clauses and words. Dordrecht: Kluwer Academic. http://dx.doi.org/10.1007/978-94-017-1986-5

Haegeman, L. (1991). Introduction to government and binding theory. Oxford: Blackwell Publishing.

Kayne, R. (2005). Movement and silence. New York: Oxford University Press. http://dx.doi.org/10.1093/acprof:oso/9780195179163.001.0001

Lansik, H., \& Saito, M. (1991). On the subject of infinitives. Proceedings of the Chicago Linguistic Society, 27, 324-343. University of Chicago.

Lasnik, H. (1999). Minimalist analysis. Massachusetts: Blackwell Publishing.

Mahmoud, M. (2000). Word order, agreement and pronominalization in standard and Palestinian Arabic. John Benjamins Publishing. http://dx.doi.org/10.1075/cilt.181

Napoli, D. J. (1993). Syntax: theory and problem. Oxford: Oxford University Press.

Pesetsky, D. (1989). The earliness principle. Massachusetts: MIT Press.

Pesetsky, D. (2000). Phrasal movement and its kin. Cambridge Mass: MIT Press.

Radford, A. (2004). Minimalist syntax. Cambridge: Cambridge University Press. http://dx.doi.org/10.1017/CBO9780511811319

Radford, A. (2009). Analyzing English sentences: a minimalist approach. Cambridge: Cambridge University Press. http://dx.doi.org/10.1017/CBO9780511801617

Rizzi, L. (1997). The finite structure of the left periphery. In L. Haegeman (Ed.), Elements of grammar (pp. 281-337). Kluwer: Dordrecht. http://dx.doi.org/10.1007/978-94-011-5420-8_7

Searle, J. R. (1972). Chomsky's revolution in linguistics. The New York Review of Books.

Searle, J. R. (1992). The rediscovery of the mind. Cambridge, Massachusetts: MIT Press.

\section{Copyrights}

Copyright for this article is retained by the author(s), with first publication rights granted to the journal.

This is an open-access article distributed under the terms and conditions of the Creative Commons Attribution license (http://creativecommons.org/licenses/by/3.0/). 